\title{
Paraspinal sinuses? Do remember renal tuberculosis
}

\author{
Chhaya Bhatt, Sambhav Lodha \\ Radiodiagnosis Department, VS Hospital and NHL Municipal Medical College, Ahmedabad, Gujarat, India \\ Correspondence to Dr Chhaya bhatt, chhayaj.bhatt@yahoo.com
}

\begin{abstract}
Summary
Approximately 4\%-8\% of patients with pulmonary tuberculosis develop clinically significant genitourinary infection. In the case being reported, a 30-year-old female, admitted with right-sided back swelling, local pain and low-grade fever. The swelling gradually increased in size over a period of 6 months and had burst spontaneously forming a pus discharging with associated localised pain and fever bringing the patient to the hospital. X-ray lumbar spine, chest and kidney ureter bladder showed no abnormalities. Ultrasound findings were suggestive of pyonephrosis with a posterior paraspinal abscess with a sinus tract within the posterior paraspinal region. CT findings were more conclusive in suggesting the sinus tract origin. Finding of tuberculous kidney and upper ureteric stricture with sinus tract opening in the posterior paraspinal region was made on CT. Right nephrectomy was done. Histopathologically proved it to be tuberculous kidney.
\end{abstract}

\section{BACKGROUND}

Extrapulmonary manifestations of tuberculosis are widespread with one of the major systems of involvement being the genitourinary. The following case report depicts the presentation with paraspinal sinus, as a complication to renal tuberbulosis with no pulmonary manifestations of the same. The genitourinary system tuberculosis accounts for $15 \%-20 \%$ of infections outside the lungs. Approximately $4 \%-8 \%$ of patients with pulmonary tuberculosis will develop clinically significant genitourinary infection.

The progression of renal tuberculosis is slow and still slower is the development of complications, with the disease mainly affecting young people. CT proves one of the most helpful modalities in diagnosing the condition and its complications for example as paraspinal sinuses.

\section{CASE PRESENTATION}

A 30-year-old female from a low socio economic staus was admitted with right-sided back swelling since 6 months. The swelling gradually increased in size and had burst spontaneously with pus discharge, localised pain and fever. On examination, there was a pus discharging sinus with surrounding inflamed and oedematous skin. X-ray lumbar spine, chest and kidney ureter bladder (KUB) were done which showed no abnormality. Blood indices, like haemoglobin, complete blood counts were normal, with elevated erythrocyte sedimentation rate (ESR) of 110 $\mathrm{mm} / \mathrm{h}$.

Ultrasound findings showed moderate hydronephrosis with internal echoes, suggestive of pyonephrosis. Dilated upper ureter with no evidence of renal or ureteric calculus. There was a posterior paraspinal abscess of approximately $3 \times 3 \mathrm{~cm}$ with sinus tract noted within the posterior paraspinal region.

CT findings suggested pyonephrosis of right kidney (figures 1 and 2),dilated and thick walled upper ureter (figure 3) with abrupt narrowing at the mid ureteric level. Distal ureter was not visualised; there was no evidence of excretion of contrast even after $6 \mathrm{~h}$ of contrast administration. Contrast injected through the sinus opening on the back, showed extension of the tract upto the upper pole (figure 4). CT finding of tuberculous kidney and upper ureteric stricture was made with sinus tract opening in the posterior paraspinal region.

Right nephrectomy was done. Histopathologically the diagnosis proved to be tuberculous kidney.

\section{INVESTIGATIONS}

X-ray lumbar spine, chest and KUB showed no abnormality.

Blood indices, like haemoglobin, complete blood counts were normal. ESRwas $110 \mathrm{~mm} / \mathrm{h}$.

Ultrasound findings were suggestive of pyonephrosis with posterior paraspinal abscess of approximately $3 \times 3 \mathrm{~cm}$ with a sinus tract in posterior paraspinal region.

CT findings suggested pyonephrosis of right kidney, dilated and thick wall upper ureter with abrupt narrowing at the mid ureteric level. Distal ureter was not visualised; there was no evidence of excretion of contrast even after $6 \mathrm{~h}$. Contrast injected through the sinus opening on the

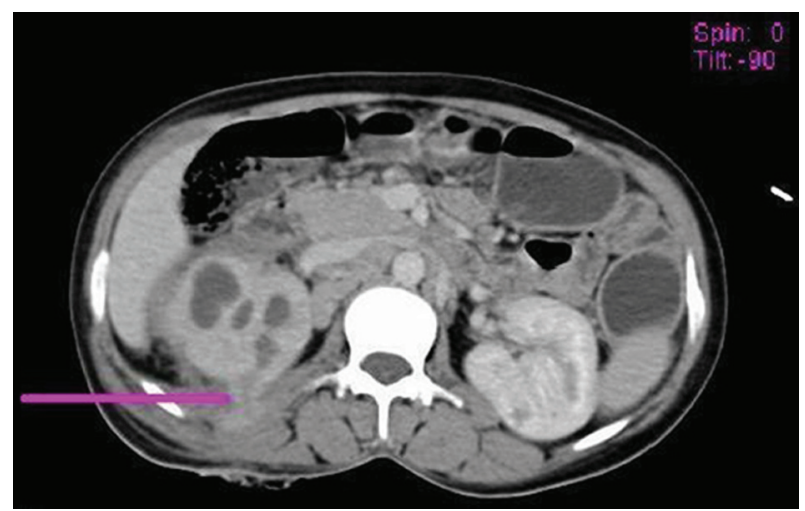

Figure 1 Hydronephrosis of right kidney, with sinus tract from upper pole. 


\section{BMJ Case Reports}

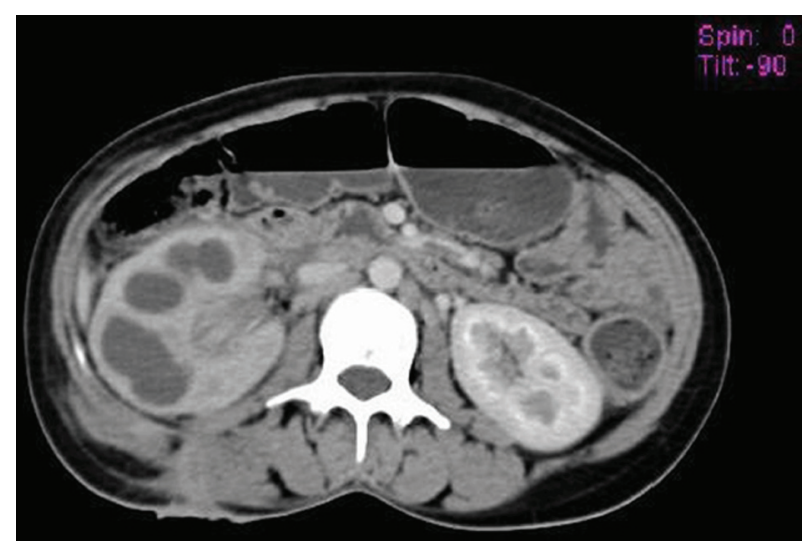

Figure 2 Hydronephrosis of right kidney, with sinus tract extending upto posterior paraspinal muscles and skin.

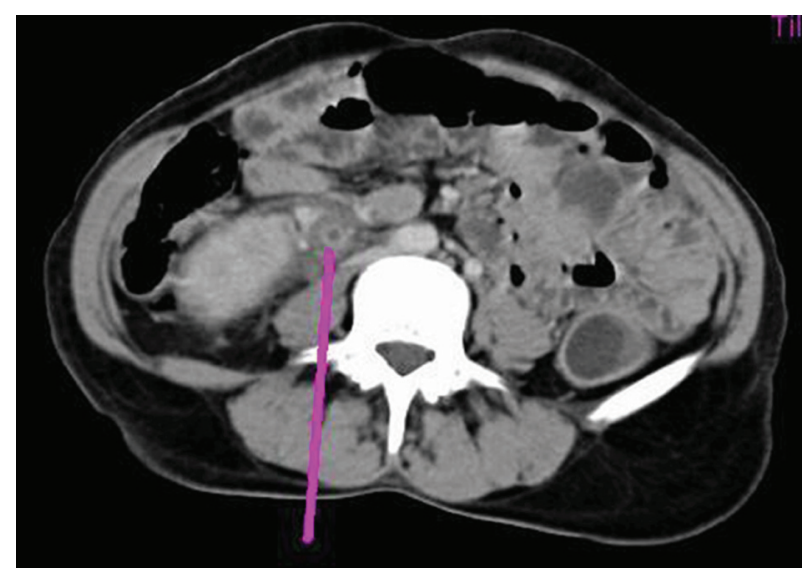

Figure 3 Dilated thick walled right upper ureter.

back, showed extension of the tract upto the upper pole. CT finding of tuberculous kidney and upper ureteric stricture was made with sinus tract opening in the posterior paraspinal region.

Right nephrectomy was done. Histopathologically the diagnosis proved to be tuberculous kidney.

\section{DIFFERENTIAL DIAGNOSIS}

- Chronic non-specific cystitis

\section{TREATMENT}

In renal tuberculosis the basic treatment is medical. Surgical excision of an infected organ, when indicated, is merely an adjunct to overall therapy.

\section{DISCUSSION}

Tubercle bacillus invades one or more organs of the urinary tract and causes chronic granulomatous infection that shows the same characteristics as tuberculosis in other organs. Urinary tuberculosis is a disease of young adults and is more common in males than in female. ${ }^{1}$

Mycobacterium tuberculosis, reaches the genitourinary organs by the haematogenous route from the lungs. The kidney is the primary sites of tuberculous infection in the urinary tract other organs become involved by either
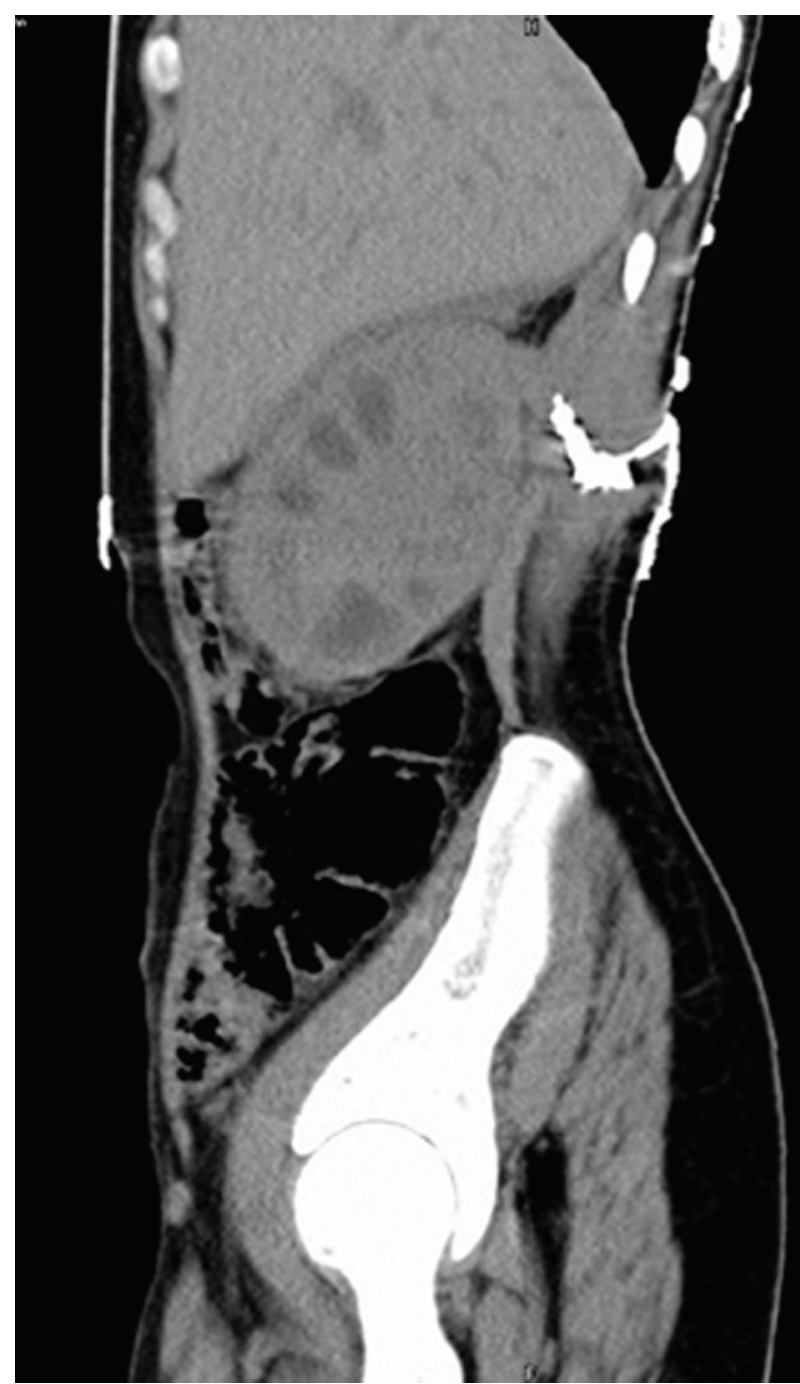

Figure 4 Contrast filled sinus tract communicating with upper pole of right kidney.

ascent (prostate to bladder) or descent (kidney to bladder, prostate to epididymis).

Tuberculosis of the kidney progresses slowly with no symptoms until the lesion has involved the calyces or the pelvis, at which time pus and organisms may be discharged into the urine. Involvement of mucosa leads to stricture and back pressure changes (hydronephrosis). Tubercle foci appear close to the glomeruli, aggregation leads to small masses. As the disease progresses, caseous breakdown of tissue occurs until the entire kidney is replaced by cheesy material, which heals by fibrosis and scarring. Calcium may be laid down in the reparative process. Acid-fast stains will usually demonstrate the organisms in the tissue.

\section{Imaging findings}

A plain film of the abdomen may show enlargement of one kidney or obliteration of the renal and psoas shadows due to perinephric abscess. Punctate calcification in the renal parenchyma is seen with renal stones seen in $10 \%$ of cases. Calcification of the ureter may be noted, but this is rare. Ultrasound demonstrates papillary 
lesions as areas of hypoechogenicity or hypoechoic foci with echogenic walls or echogenic non-shadowing lesions. A sloughed calyx is seen as an echogenic flap separated from the normal caliceal wall. Large liquefying conglomerate cavities or dilated calyces formed as a result of infundibular stricture appear as hypoechoic nodules or masses. The communicating tract from a cavity appears as a sonolucent track entering the dilated calyx. Ultrasonography (USG) may characteristically show uneven caliectasis without renal pelvis dilatation. It may also demonstrate hydronephrosis, hydroureter, parenchymal calcification and perinephric abscess. USG may detect focal irregularity or thickening of the bladder wall with reduced capacity.

Excretory urograms can be diagnostic if the lesion is moderately advanced. The typical changes include (1) a 'moth-eaten' appearance of the involved ulcerated calyces, (2) obliteration of one or more calyces, (3) dilatation of the calyces due to ureteral stenosis from fibrosis, (4) abscess cavities that connect with calyces. (5) Scarring can cause sharp angulations of the renal pelvis (Kerr kink). ${ }^{2}$ (6) Ureteral involvement manifests as dilatation and mucosal irregularity (saw tooth ureter), which progress and leads to the formation of strictures and ureteral shortening (pipe-stem ureter). ${ }^{3}$ Fusion of multiple strictures may create a long, irregular narrowing produce a 'beaded' or 'corkscrew' ureter, ${ }^{2}$ (7) absence of function of the kidney due to complete ureteral occlusion and renal destruction (autonephrectomy). In the early stages, the only radiological abnormality may be irregularity or destruction of one or more papillae. Cystogram may reveal ureteral reflux. CT is helpful in determining the extent of renal and extra renal spread of disease, ${ }^{4}$ for identifying renal calcifications and coalesced cortical granuloma containing either caseous or calcified material. CT findings include focal or global cortical thinning, parenchymal scarring, dilated caliceal system, ureteral dilatation. Fibrotic strictures of the infundibula, renal pelvis, and ureters may be seen at contrast-enhanced CT and are highly suggestive of tuberculosis. ${ }^{4}$ MRI description of urinary tract tuberculosis is limited. MRI with MR urography can be used to evaluate nonfunctioning kidney, especially the obstructive form for demonstration of ureteric involvement.

\section{Learning points}

- The patient hailed from a very low socio economic background, thus we went with a step wise approach to limit our investigations keeping in mind about the factors relating to patients affordability, MRI's difficult availability along with the search for the best diagnostic modality for the patient. The final decision was thus achieved by the CT scan.

- Approximately $4 \%-8 \%$ of patients with pulmonary tuberculosis develop clinically significant genitourinary infection.

- Urinary tuberculosis is a disease of young adults and is more common in males than in female.

- Urinary tuberculosis occurs commonly as the primary form, without any pulmonary manifestations or signs.

- USG may characteristically shows uneven caliectasis without renal pelvis dilatation, hydronephrosis, hydroureter, parenchymal calcification and perinephric abscess. USG also detects focal irregularity or thickening of the bladder wall with reduced capacity.

- CT is helpful in determining the extent of renal and extra renal spread of disease, for identifying renal calcifications and coalesced cortical granuloma containing either caseous or calcified material.

- MRI description of urinary tract TB is limited.

- Lastly paraspinal sinuses should always be looked in for renal tuberculosis as the one of primary aeitologies.

\section{Competing interests None.}

Patient consent Obtained.

\section{REFERENCES}

1. Farer LS, Lowell AM, Meador MP. Extrapulmonary tuberculosis in the United States. Am J Epidemiol 1979;109:205-17.

2. Khandelwal N, Chowdhury V, Gupta AK. AIIMs-MAMC_PGI Imaging Series. Diagnostic Radiology Genitourinary Imaging. Third Edition. New Delhi: Jaypee Brother Medical Publishers 2009

3. Leder RA, Low VH. Tuberculosis of the abdomen. Radiol Clin North Am 1995:33:691-705.

4. Goldman SM, Fishman EK, Hartman DS, et al. Computed tomography of renal tuberculosis and its pathological correlates. J Comput Assist Tomogr 1985;9:771-6.

5. Wang LJ, Wong YC, Chen CJ, et al. CT features of genitourinary tuberculosis. J Comput Assist Tomogr 1997;21:254-8.

This pdf has been created automatically from the final edited text and images.

Copyright 2012 BMJ Publishing Group. All rights reserved. For permission to reuse any of this content visit http://group.bmj.com/group/rights-licensing/permissions.

BMJ Case Report Fellows may re-use this article for personal use and teaching without any further permission.

Please cite this article as follows (you will need to access the article online to obtain the date of publication).

Bhatt C, Lodha S. Paraspinal sinuses? Do remember renal tuberculosis. BMJ Case Reports 2012;10.1136/bcr.12.2011.5445, Published XXX

Become a Fellow of BMJ Case Reports today and you can:

- Submit as many cases as you like

- Enjoy fast sympathetic peer review and rapid publication of accepted articles

- Access all the published articles

- Re-use any of the published material for personal use and teaching without further permission

For information on Institutional Fellowships contact consortiasales@bmjgroup.com

Visit casereports.bmj.com for more articles like this and to become a Fellow

Keep up to date with all published cases by signing up for an alert (all we need is your email address) http://casereports.bmj.com/cgi/alerts/etoc 